\title{
Christ - A Contradiction: A Defense of Contradictory Christology
}

\begin{abstract}
The fundamental problem of Christology (as Richard Cross famously coined it) is the apparent contradiction of Christ as recorded at Chalcedon. Christ is human (with everything entailed thereby) and Christ is divine (with everything entailed thereby). Being divine entails (among many other of God's properties) being immutable. Being human entails (among many other of our essential properties) being mutable. Were Christ two different persons (viz., a human person, a divine person) there'd be no apparent contradiction. But Chalcedon rules as much out. Were Christ only partly human or only partly divine there'd be no apparent contradiction. But Chalcedon rules as much out. Were the very meaning of 'mutable' and/or 'immutable' (or other such predicates) other than what they are, there'd be no apparent contradiction. But the meaning is what it is, and changing the meaning of our terms to avoid the apparent contradiction of Christ is an apparent flight from reality.

What, in the end, is the explanation of the apparent contradiction of Christ? Theologians and philosophers have long advanced many consistency-seeking answers, all of which increase the metaphysical or semantical complexity of the otherwise strikingly simple but radical core of Christianity's GodMan. In this paper, I put the simplest explanation on the theological table: namely, Christ appears to be contradictory because Christ is contradictory (i.e., some predicate is both true and false of Christ, and hence some logical contradiction is true of Christ). This explanation may sound complicated to the many who are steeped in the mainstream account of logic according to which logic precludes the possibility of true contradictions. But the mainstream account of logic can and should be rejected. Ridding theology of the dogma of mainstream logic illuminates the simple though striking explanation of the apparent contradiction of Christ namely, that Christ is a contradictory being. Just as the simplest explanation to the apparent roundness of the earth has earned due acceptance, so too should the simplest explanation of the apparent contradiction of Christ.
\end{abstract}

Journal of Analytic Theology, Vol. 7, June 2019

10.12978/jat.2019-7.090202010411

(c) 2019 Jc Beall • (C) 2019 Journal of Analytic Theology 
The doctrine of the Incarnation has long perplexed believers and non-believers alike. What is perplexing is the paradoxical appearance of an Incarnate God, who is supposed to be omnipotent. Christ is supposed to be God, and yet also is supposed to have a finite corporeal body, feel pain, and have other properties of creatures, whereas God is supposed to be none of these things.

-Allan Bäck (1982)

[T]here is a point at which the student of Christology becomes a student of Logic; ... a point at which [the student] has to make use of the concept of incompatibility and entailment; a point at which [the student] has to answer a charge of self-contradiction.

—C.J. F. Williams (1968)

This paper aims to do two things. First, the paper aims to illuminate the role that logic itself plays in theology (and any other discipline), and also to review a particular account of logic itself. Given the breadth of these topics my discussion aims only to convey a basic sketch of logic and its role, leaving a fuller discussion for elsewhere. The second aim of the paper is to defend the viability of 'Contradictory Christology' whereby the right response to the fundamental problem of Christology (viz., Christ's having apparently complementary - contradiction-entailing - natures) is to accept the familiar contradictions.

\section{The fundamental problem of Christology}

The fundamental problem of Christology is the apparent contradiction of Christ's having two apparently complementary - contradiction-entailing - natures, the divine and the human (see Cross 2011). This problem may be sharpest for Conciliar Christology, as in Timothy Pawl's work $(2014 ; 2016)$; however, the prima facie problem is clear for any orthodox or traditional Christianity according to which Christ has two apparently complementary natures.

Here is one way to see the fundamental problem:

1. Christ is immutable (in virtue of Christ's divine nature).

2. Christ is mutable (in virtue of Christ's human nature).

3. Therefore, Christ is both mutable and not mutable (via logic).

This argument relies not only on the familiar (but suppressed) entailment from $x$ is immutable to $x$ is not mutable, but also on the familiar 'transference principle' (in effect, a generalized 'communicatio idiomatum' doctrine) that

P0. Something that has (or exemplifies) a nature $\mathrm{N}$ has whatever properties are entailed by having nature $\mathrm{N}$. 
The argument also assumes the orthodox view (from conciliar texts) that

P1. Christ has a divine nature (entailing immutability) and independently and without diminishment also has a human nature (entailing mutability). ${ }^{1}$

The history of Christian theology, and in particular that of Christology, is peppered with sophisticated ways to modify (P0) or (P1) in response to the apparent contradiction of Christ. $^{2}$ (P0) is a default metaphysical (i.e., extra-theological) principle about the relation between natures and entities that have them. Overturning (P0) requires good reason, and theologians have pointed to the fundamental problem (above) - the glaring contradiction in (3) - as a good reason to overturn the principle. Similarly, the distinctly theological principle (P1) has been rejected or modified or non-standardly interpreted in ways that aim to avoid the fundamental problem - to avoid the apparent contradiction of Christ. Against these traditions that are fueled by a rejection of (3) I shall assume both the (orthodox) principle (P1) together with the flat-footed metaphysical principle (P0). In what follows (P1) and (P0) are held fixed. ${ }^{3}$

Rejecting all logical contradictions (i.e., sentences of the form it is true that $p$ and it is false that $p),{ }^{4}$ and a fortiori any contradiction in our theology, requires a rejection of (1) or (2) or the step to (3). But there is another way, namely, to accept (3) - that it's true that Christ is mutable and it's false that Christ is mutable. What immediately removes this option from the theological table is the view that logic itself rules out the possibility of such true but logically contradictory claims.

I am not in position to argue that the true Christology is logically contradictory. But that such a view is both viable and motivated is what I aim to defend. Once the view is allowed a place at the table debate can move forward on whether it is the most natural and indeed true Christology.

The barriers in the way of accepting a logically contradictory Christology are built on an incorrect view of logic itself. Accordingly, a large amount of space in this paper is spent on logic itself. I begin in $\S 2$ with a sketch of the role of logic in our theories - and in theology in particular. After specifying the role of logic I give an account of logic itself, an account of which entailment relation is logical entailment (see §3). The given account of logic differs from the standard (so-called classical-

\footnotetext{
${ }^{1}$ I believe that 'independently and without diminishment' is redundant but I use it to emphasize the orthodox view in juxtaposition with the many other views whereby some hybrid or conflated nature, or something other than the having of two target natures, is involved. (The words are ultimately redundant because having a nature $\mathrm{N}$ is having that nature. And while having two complementary natures, $\mathrm{N} 1$ and $\mathrm{N} 2$, is strikingly rare it is nonetheless a case of having $\mathrm{N} 1$ and also having $\mathrm{N} 2$ - having (exemplifying) each of them.)

2 See, for example, Adams 2006; Crisp 2007; 2009; and Cross 2005; 2011.

${ }^{3}$ I also hold fixed the familiar entailment from $x$ is immutable to $x$ is not mutable (and likewise for other familiar 'negative' predicates and logical negation). This has recently been questioned by Timothy Pawl (2015), but, except for some discussion in §5, I simply assume this standard entailment. (I plan to provide a fuller discussion of Pawl's given work in a larger project of which this paper is a part.)

${ }^{4}$ If one wishes, one may replace my use of 'sentences' (by which I mean declarative sentences, ones that declare something about the world) with 'propositions'.
} 
logic) account; but the given account is both well-known and well-motivated in the philosophy of logic. My aim in this paper is not to rehearse the wide-ranging debates that motivate the target account of logic; my aim is to put the account on the theological table as a viable account, leaving fuller debate to cited sources. After putting the role and specific account of logic on the table I turn to a defense of Contradictory Christology, first advancing the basic position (see §4) and then defending it against various objections (see §5). The paper closes in $\S 6$ with remarks towards future (analytic) theology.

\section{The role of logic in general and in theology}

Logic is the common foundation of all (so-called closed) theories; it's part of the (extra-logical, stronger) 'consequence' or 'entailment' relation for our true theories. These ideas can be spelled out with reference to logic's role in theology.

\subsection{Theology and consequence}

Christian theology is a theory of God, just as macro physics is a theory of the macrophysical world and just as mathematical theories are theories of their respective mathematical phenomena (numbers, categories, sets, whathaveyou). When we construct our theology (our theory of God) we begin by adding truths of God, including (for example) that God is triune, that Christ has two (complementary) natures, that God is omniscient, and so on for whatever we, as theologians (as theorists of God), take to be true of God - including, of course, truths about what God is not, what is false of God (e.g., that it is false that God is limited, false that God is evil, etc.). ${ }^{5}$

When theorists aim to construct a true theory, they aim to construct as complete a theory as possible. In particular, the resulting theory should not only contain the initial thrown-in truths (e.g., that God is triune, that Christ has two natures, etc.); the theory should also contain whatever follows from the truths in the theory; it should contain all of the consequences of the theory's claims. The question is: what is meant by 'follows from' and 'consequences' in this context?

This is where consequence relations enter. A consequence relation for a set of claims is an entailment relation. ${ }^{6}$ In particular, a consequence relation tells you what claims follow, according to that relation, from your given set of claims, where 'follows from' is understood as entailment - as necessary truth preservation over some target space of possibilities.

\footnotetext{
${ }^{5}$ The source of our knowledge of theological truth is an issue for epistemology; my topic in this paper concerns only the record - the theory - of our true theology, not its source.

${ }^{6}$ In more detail: I assume that target consequence relations are what are classified as 'closure relations' along the lines initially explored by Tarski 1956 . This imposes certain technical constraints on what counts as a consequence relation, but for my purposes I leave the details aside. (Everything I say is compatible with the requisite conditions on closure relations.)
} 
Example: consider the theory of knowledge. That theory contains the following truth:

4. It is known that $1+1=2$.

And there are many other thrown-in truths of that form: it is known that $p$, where $p$ is some known truth. But there are many 'it is known that...'-free claims in our true theory of knowledge too. An example:

\section{5. $1+1=2$.}

Why is (5) in our true - and as-complete-as-possible - theory of knowledge? Answer: because (5) is a consequence of (4), and (4) is in our theory of knowledge. Our best theory of knowledge has a consequence relation according to which, for any sentence $p$ in the language, $p$ follows from - is entailed by, is a consequence of - the claim it is known that $p$.

There is nothing special about the theory of knowledge. The construction of true theories involves the construction of consequence (closure) relations for those theories - an entailment relation that serves to 'complete' the theory (as far as possible) by churning out all of the truths that follow from (that are entailed by) the claims in the theory. Our true theory of (for example) temporal phenomena has it that it is false that $p$ follows from it is always true that it is false that $p$; our true theory of (for example) metaphysical possibility has it that it is metaphysically possible that $p$ follows from it is true that $p$.

Such theory-specific consequence relations are just that: theory-specific. The consequence relation governing knowledge claims (i.e., claims of the form it is known that ...) is not involved in the consequence relation governing the theory of arithmetic (unless the theory is also in part about explicit knowledge of arithmetic). The theorist's task is to construct a set of truths about a target phenomenon and close that set of truths under the consequence relation that, by the theorist's lights, is the right relation to 'complete' the true theory of the given phenomenon.

And theology is no different. Theologians must not only add various basic truths about God but also 'complete' (as far as possible) the theory via a consequence relation. According to the consequence relation of true Christian theology, that it is false that $p$ follows from any sentence $p$ that claims the existence of a rival god or, for that matter, any sentence $p$ that limits God's powers or authority. While theologians have not always been explicit about their target consequence relation they have nonetheless assumed one in their systematic pursuit of the 'complete' (as possible) truth of God - the true theology.

Without a consequence (closure) relation our theories remain inadequate; they fail to contain truths that are entailed by the given set of truths. Inasmuch as theorists, and theologians in particular, aim to give as complete a theory of the target phenomenon as possible, the reliance on a consequence relation for our theory is required.

But what have such theory-specific consequence relations to do with logic's role in theories? 


\subsection{Consequence and (formal) logical consequence}

Logic is a very special consequence (entailment, closure) relation. Logic is the common core of all (closed) theories; ${ }^{7}$ it is at the bottom of all of the (extra-logical, theory-specific) consequence relations of our true theories. While the theory-specific consequence relation for our theory of knowledge is different from the consequence relation for our theory of arithmetic (or necessity, or God) the two consequence relations share a common elementary core: namely, logic. Logic itself does not say anything peculiar about knowledge claims, arithmetical claims, modal claims or theological claims; logic ignores the specific subject matter of those sorts of claims (be it knowledge, arithmetic, modality or God) and treats them as it treats claims about any subject matter whatsoever. In this way, logic is said to be 'universal' and 'topic-neutral'.

Logic's universality and foundational role in all of our true (closed) theories is achieved by logic's narrow focus: it focuses only on so-called logical vocabulary. Chief examples of logical vocabulary (and, for purposes of this paper, the only canvassed examples) are the so-called boolean quartet: ${ }^{8}$

- $\quad$ Truth (or null) operator: it is true that...

- $\quad$ Falsity (or negation) operator: it is false that...

- Conjunction:....and...

- Disjunction: either...or ...(or both)

Logical consequence - logical entailment - is a so-called formal relation: it looks only at certain 'forms' of sentences, namely, the ones individuated in terms of the logical vocabulary. In particular, logic recognizes only a limited list of sentence forms:

- Atomic sentences: any sentence which is free of logical vocabulary. ${ }^{9}$

- $\quad$ 'Nullations' (truth claims): any sentence of the form it is true that ...10

- Negations (falsity claims): any sentence of the form it is false that ...

- Conjunctions: any sentence of the given (logical-conjunction) form, namely, ... and ... where 'and' is logical conjunction.

- Disjunctions: any sentence of the given (logical-disjunction) form, namely, ... or ... where 'or' is logical disjunction.

\footnotetext{
${ }^{7}$ For present purposes (skipping technical details), think of a closed theory as a set of claims closed under a consequence relation such that (among other things) if a sentence is a consequence of something in the theory then that sentence is in the theory.

${ }^{8}$ This is an incomplete list of logical vocabulary. The logical vocabulary extends beyond the list below to the standard first-order vocabulary involving logical quantifiers (though not, on my view, an identity predicate). Again, for present purposes it suffices to focus on the following basic vocabulary.

${ }^{9}$ Throughout, 'sentence' shall be used to pick out declarative sentences - sentences that declare something about reality.

10 This category is often ignored, since logic treats its truth operator as (logically) redundant. In much of what follows I follow suit by ignoring, for the most part, the truth operator.
} 
Logic recognizes only the foregoing kinds (forms) of sentences, and it classifies entailments only in terms of the limited list of forms. Important to note is that logic treats all atomic claims on par: logic itself sees no difference in logically relevant content between 'God is good' and 'Hogwarts is fictional'; such a difference - and the resulting difference in entailments - arises only in extra-logical, theory-specific consequence relations.

Examples of common logical entailments are the following, where $\wedge$ is logical conjunction, $\vee$ logical disjunction, $\neg$ the falsity (or negation) operator, $\dagger$ the truth (or null) operator, and $p$ and $q$ are any (declarative) sentences:

- $\quad p$ logically entails $p \vee q$.

- $\quad p \wedge q$ logically entails $q$ (and also $p$ ).

- $\quad \neg p \wedge \neg q$ is a logical consequence of $\neg(p \vee q)$ (and vice versa).

- $\quad \neg p \vee \neg q$ is a logical consequence of $\neg(p \wedge q)$ (and vice versa).

- $\quad p$ logically entails $\nmid p$ (and vice versa).

- $\quad \neg \neg p$ logically entails $\nmid p$ (and vice versa).

Logic is formal in that its consequence relation holds only in virtue of the given logical forms. For example, anything of the form $\neg p \wedge \neg q$ logically entails anything of the form $\neg(p \vee q)$. And logic says nothing about any 'forms' that go beyond its recognized list.

Logical entailment, like any entailment relation, is a relation of necessary truth preservation over relevant possibilities - in this case, the so-called logical possibilities (i.e., the possibilities recognized by logic). The recipe for logical entailment is absence of counterexample:

Let $X$ be a set of sentences, and $p$ any sentence. Then $X$ logically entails $p$ (i.e., $p$ is a logical consequence of $X$ ) if and only if there is no possibility in which everything in $X$ is true but $p$ is untrue. (A counterexample is a possibility in which everything in $X$ is true but $p$ untrue.)

Here, 'possibility' picks out whatever logic recognizes as possible. While there is ongoing debate about which possibilities are logical possibilities (i.e., recognized by logic's entailment relation) one matter is settled: logic plays its universal, foundational role in our theories by recognizing the widest space of possibilities. In physical theory, the space of possibilities is restricted to those (logical) possibilities that obey physical laws. In arithmetic the space of possibilities is restricted to those (logical) possibilities that obey the laws of arithmetic. In theology the space of possibilities is restricted to those (logical) possibilities that obey the truths about God.

Logic is the common core of all theory-specific consequence relations in virtue of logic's recognizing the widest space of possibilities. The possibilities in terms of which a theory-specific entailment relation is defined (i.e., in terms of which the theory's class of would-be counterexamples is defined) are one and all logical 
possibilities. The theory-specific consequence relations restrict the space of logical possibilities in order to focus on target, phenomenon-specific entailments (i.e., entailments that aren't recognized by all consequence relations for true theories); but they do not reject or otherwise transgress logical entailments.

In the end, logic's role in theology is its role in all of our true and 'complete' (as possible) theories: namely, to deliver the logical consequences of the claims in our theories. Logic is involved in all consequence relations for our true theories, including our theory of God (i.e., our theology). Logic achieves this universal role - the foundation of all entailment (or closure) relations on our true theories - in virtue of recognizing the widest space of possibilities. It's not that 'anything goes' by logic's lights; but a vast array of otherwise very strange possibilities is recognized by logic.

\subsection{Logic and standard logic}

Since Aquinas, whose work reflected (one reading of) Aristotle, the range of logical possibilities has standardly been thought to be narrower than I, along with other socalled subclassical-logic theorists, take it to be. The standard class of possibilities is modeled by so-called classical-logic models. The term 'classical' does not denote Aristotle's logic, since Aristotle's logic was both impoverished (lacking, e.g., adequate quantificational resources and much else) and also arguably at odds with so-called classical logic. In fact, what is today called 'classical logic' is a fairly recent construction ushered in largely by philosophers Boole, Peirce, Ladd-Franklin, Frege, Russell and Whitehead.

This paper is not the place to rehearse the history of logic or the many debates on whether the standard account of logic gets things right. By my lights, for reasons argued elsewhere, ${ }^{11}$ the correct account of logic is in fact weaker than the standard one: the space of logical possibilities is much wider than the standard account takes it to be. For present purposes my aim is only to present the weaker account (one that I believe to be the right account), leaving debate for other venues.

Nothing in orthodox Christianity demands the standard (twentieth-century) account of logic. Responsible theorizing calls for an exploration of alternative options. My chief aim is to advance what I take to be a viable Christology opened up by an alternative (though nonetheless mainstream) account of logic. By my lights, theology benefits from an informed view of logic; and ignoring the subclassical account(s) is not only unmotivated; it may in fact preclude the true Christology.

\section{Logic: subclassical}

The aim of this section (and its subsections) is to present, as concisely as possible (without obliterating user-friendliness), the target account of logic: namely, what is called 'first-degree entailment' (FDE), most famously explored by Anderson, Belnap

11 See for example, Beall 2009; Belnap 1977; Dunn 1966; 1976; Priest 1987; 2004; Routley 1979; and Routley and Meyer 1976. 
and Dunn, ${ }^{12}$ but applied on a wide range of philosophical fronts by many philosophers. I believe but, for present purposes, shall only assume that FDE is the correct account of logic (qua universal consequence relation in the sense given above). ${ }^{13}$ While arguing for the truth of this assumption is too much for the present paper, I shall defend the claim in some of the objections and replies (see §5).

\subsection{Formal language}

As above (see §2.2), logical consequence is a formal entailment relation; it holds in virtue of 'logical form'. The target forms are specified by logical vocabulary. Because the main action of the present paper can be seen at the so-called propositional (or sentential) level, we restrict the following to just that level - indeed, restricting to just the so-called monadic predicates for simplicity. ${ }^{14}$

Following standard practice we use models - and an artificial, formal 'model language' - to specify the target entailment relation. Entailment, as above, is necessary truth-preservation over a space of relevant possibilities. In logic these possibilities are modeled by some sort of mathematical structure (sets, functions, relations); and the idea of a sentence's being true (false) at a possibility is modeled by relations that are defined on the given structures. Despite the level of mathematical abstraction the target remains always on 'real logical consequence' for our 'real language'. The 'logically valid forms' that are generated by the mathematical account are advanced as the 'real' logically valid forms.

In what follows the syntax (grammar, vocabulary, and definition of sentences) is presented first, followed by the semantics (model of truth and falsity conditions for the sentences), followed by the central target: namely, the logical consequence relation (logic).

\subsubsection{Syntax}

The basic vocabulary (building blocks) of the language are as follows.

1. Vocabulary:

a. Logical Expressions:

i. Unary connectives: $\dagger$ and $\neg$

ii. Binary connectives: $\wedge$ and $\vee$

b. Extralogical expressions:

i. Unary predicates: ' $P$ ', ' $Q$ ', ' $R$ ' with or without numerical subscripts (unary: they take one name to make a sentence)

\footnotetext{
12 Anderson and Belnap 1975; Anderson, Belnap, and Dunn 1992; Dunn 1966; 1976.

${ }^{13}$ For arguments towards this conclusion see Beall 2017.

${ }^{14}$ A generalization to the full stock of (standard) first-order vocabulary is not difficult but, again, is not necessary for purposes of this paper. (The presentation here involves monadic predicates - versus the even simpler 'sentential variables' - to give at least some sense of how atomic sentences are modeled as both true and false.)
} 
ii. Names: lowercase letters of English, with or without numerical subscripts

c. Alogical expressions:

i. Punctuation: right and left parentheses (viz., ')' and '(')).

The syntax, while on its own (apart from a semantics) meaningless, is motivated by our target logic. In particular, the unary connectives ('unary' because they take exactly one sentence to make a sentence) will be treated in the semantics as logic's truth and falsity operators, and the binary connectives will be treated as the logical conjunction and disjunction operators.

Worth noting is that the predicates and names in the class of extralogical expressions are not necessary for specifying the logic; they are in there to add (I hope) some illumination on how atomic sentences are formally interpreted (see semantics below). One can simplify the syntax by ignoring any structure in atomic sentences and simply having standard 'propositional letters' as atomic sentences.

The sentences of the language are defined as follows.

2. Sentences of the language:

a. Atomics: let $G$ be a predicate and $\eta$ a name. Then $G$ followed by $\eta$ (viz., ' $G \eta$ ') is an atomic (sentence).

b. Molecular (Compound): If $A$ and $B$ are sentences of the language, then so too are $\dagger A, \neg A,(A \wedge B)$ and $(A \vee B)$.

c. Nothing else is a sentence of the language (except what follows from the first two clauses).

Examples of atomic sentences are $P a, R b_{22}$, and $Q d$. (See the list of predicates and the list of names under vocabulary, and then consult the definition of atomics above.) Examples of molecular sentences (i.e., sentences that contain at least one logical expression) are $\dagger P a,\left(\neg R b_{22} \vee(Q d \wedge P a)\right)$, and $(Q d \vee P a) .{ }^{15}$

\subsubsection{Semantics: towards truth and falsity conditions}

The aim, again, is to precisely specify the logical consequence relation, which is an entailment relation, which is a truth-preserving relation over relevant possibilities. To specify the target truth-preserving relation for our model language we need to have an account of truth and falsity conditions for the sentences of the language.

As in standard accounts of logic a sentence's having a truth value (or, generally, 'semantic status') boils down to what's happening at the atomic level. In other words, our logical connectives are all 'truth-functional' in a familiar way: the semantic value

\footnotetext{
15 To see that these are in fact official sentences, consult the definition of sentences above and simply let $A$ be $P a, B$ be Qd, in which case, for example, $(Q d \wedge P a)$ counts as a sentence; and now let $A$ be $R b_{22}$, in which case, $\neg R b_{22}$ counts as a sentence; and now let $A$ be $\neg R b_{22}$ and $B$ be $(Q d \wedge P a)$, in which case $\left(\neg R b_{22} \vee(Q d \wedge P a)\right)$ counts as a sentence.
} 
of a sentence is a function of the semantic values of the atomic sentences. In this way, the semantic action takes place at the atomic level.

Atomic sentences get to have a semantic value (be it truth, falsity or something else) in a familiar way. Examples: if the subject term of the sentence picks out (denotes) an object of which the predicate term is true, then the given sentence is (at least) true; if the subject term of the sentence picks out an object of which the predicate term is false, then the given atomic sentence is (at least) false. ${ }^{16}$ So, atomic sentences get their values in terms of what their parts (in our simple language, a unary predicate and a name) denote.

In general, we think of the 'possibilities' involved in logic as modeled by certain mathematical models. For our purposes, models contain both a denotation function $\delta$, which supplies a semantic value to predicates and names, and a domain $D$ of objects - namely, all of the objects that exist according to the model.

\subsubsection{Atomic sentences}

A predicate $G^{\prime}$ 's semantic value is modeled as a pair $\left\langle G^{+}, G^{-}\right\rangle$, where $G^{+}$(the so-called extension) contains all of the objects of which the predicate $G$ is true, and $G^{-}$(the socalled antiextension) contains all of the objects of which $G$ is false. Where $\delta$ is a denotation function for a model, the predicate $G$ is given the semantic value $\delta(G)=\left\langle G^{+}, G^{-}\right\rangle$in a model, while each name $\eta$ is given a denotation $\delta(\eta)$ from the set $D$ of objects in the model. These resources are then used to provide a semantic status for atomic sentences.

Truth and falsity conditions for atomic sentences as follows, where $\delta$ is the 'denotation function' of a given model:

- $\quad$ Truth in a model: Atomic $G \eta$ is true-in-a-model iff $\delta(\eta)$ is in $G^{+}$.

- $\quad$ Falsity in a model: Atomic $G \eta$ is false-in-a-model iff $\delta(\eta)$ is in $G^{-}$.

Of paramount importance is the question of what constraints logic imposes on the interpretation of predicates (i.e., on the denotation of predicates).

The issue may be seen by considering two salient constraints.

- Exhaustion: every model is 'exhaustive' with respect to every predicate in the sense that every object in the domain is either in $G^{+}$or in $G^{-} .{ }^{17}$

- Exclusion: every model is 'exclusive' with respect to every predicate in the sense that no object in the domain is in both $G^{+}$and $G^{-} .{ }^{-18}$

On the so-called classical account, logic imposes both exhaustion and exclusion. Logic, on that account, is exhaustive: it recognizes no possibility in which an object fails to

\footnotetext{
${ }^{16}$ The 'at least' is redundant in standard (so-called classical) accounts of logic; but it is not redundant in the account advanced here, namely, FDE. This will be clear below.

${ }^{17}$ In set-theoretic notation: $G^{+} \cup G^{-}=D$, where $D$ is the domain of the model.

${ }^{18}$ In set-theoretic notation: $G^{+} \cap G^{-}=\varnothing$, where $\emptyset$ is the empty set.
} 
be in either the extension or antiextension of a predicate - no possibility in which a predicate fails to be either at least true of the object or at least false of the object. (This rules out the logical possibility of 'truth-value gaps', where a sentence is neither true nor false for some reason - a sort of indeterminacy of semantic value.) Moreover, logic, on the 'classical' account, is exclusive: it recognizes no possibility in which an object falls into both the extension and antiextension of a predicate - no possibility in which a predicate is both true and false of an object. (This rules out the logical possibility of 'truth-value gluts', where a sentence is both true and false for some reason - a sort of overdeterminacy of semantic value.)

These constraints are overly strict from an alternative (viz., FDE) account of logic. The issue is too complex to argue here, but at least one consideration can be advanced. In particular, the classical-logic constraints (above) are very, very wellmotivated when one focuses one's attention on a standard diet of examples from sciences like mathematics - the very diet to which the classical-logic account was historically directed. But reality is more than just mathematics. Reality appears to contain some surprising (however rare) phenomena that don't naturally fit into the confines a classical-logic assumptions. Language's strange phenomena (e.g., vagueness, paradoxical phenomena, and more) don't obviously fall into the confines of (classical-logic-governed) mathematics. Moreover, and most pressing for present purposes, reality involves a theological realm and its complex phenomena - including, from orthodox Christian theology, the fundamental problem of Christology. It may well be that all such extra-mathematical phenomena are truly described by a classical-logic-like consequence relation; but there is no obvious reason to think that logic itself demands as much.

Logic, on the FDE account, imposes neither exhaustion nor exclusion on its predicates. A model - representing one of the possibilities that logic recognizes - may treat a predicate as exclusive; it may treat it as exhaustive; it may treat it as both. But on the FDE account there are also models in which a predicate may be neither true nor false of an object - the resulting atomic sentence 'gappy' in the model - and there are models in which a predicate may be both true and false (a 'glutty' model).

What the FDE account does not do is reject any classical-logic models. The account accepts all classical-logic models as genuine models (as representations of possibilities that logic recognizes); the account simply expands the space of models to recognize ones that go beyond the narrow confines of the classical-logic space. What this means is that if there is a classical-logic counterexample to an argument, then there is an FDE counterexample too - since FDE's spaces of models includes the narrower classical-logic ones. But the converse fails: FDE recognizes more possibilities (more genuine models) than the classical-logic perspective allows, and so recognizes more candidate counterexamples than classical logic recognizes.

\subsubsection{Semantic values for molecular sentences}

Atomic sentences achieve their semantic values - or semantic statuses - as above (see §3.1.3). Models are likewise as above, with no constraint that requires exhaustion or exclusion on predicates. This gives four possibilities for an atomic sentence: 
- Just true: the denoted subject (i.e., denotation of the name) is in the extension of the given predicate but not in the antiextension.

- Just false: the denoted subject is in the antiextension of the given predicate but not in the extension.

- Gap (gappy): the denoted subject is in neither the extension nor the antiextension.

- Glut (glutty): the denoted subject is in both the extension and the antiextension.

Following terminology from Belnap 1977 we shall say that an atomic sentence is at least true (false) iff the denoted subject is at least in the extension (at least in the antiextension) of the given predicate. Then truth and falsity conditions for molecular sentences may be given as follows, where $A$ and $B$ are any sentences of the language:

- $\quad$ Nullations: $\dagger A$ is at least true in model $m$ iff $A$ is at least true in model $m$.

- $\quad$ Nullations: $\dagger A$ is at least false in model $m$ iff $A$ is at least false in model $m \cdot{ }^{19}$

- $\quad$ Negations: $\neg A$ is at least true in model $m$ iff $A$ is at least false in model $m$.

- $\quad$ Negations: $\neg A$ is at least false in model $m$ iff $A$ is at least true in model $m$.

- $\quad$ Disjunctions: $A \vee B$ is at least true in model $m$ iff either $A$ is at least true in $m$ or $B$ is at least true in $m$.

- $\quad$ Disjunctions: $A \vee B$ is at least false in model $m$ iff both $A$ is at least false in $m$ and $B$ is at least false in $m$.

- $\quad$ Conjunctions: $A \wedge B$ is at least true in model $m$ iff both $A$ is at least true in $m$ and $B$ is at least true in $m$.

- $\quad$ Conjunctions: $A \wedge B$ is at least false in model $m$ iff either $A$ is at least false in $m$ or $B$ is at least false in $m$.

What is important to emphasize, as discussed again below, is that these truth and falsity conditions are precisely the same conditions used in the standard classical-logic account. The difference, of course, is that the classical-logic account ignores the logical possibilities of 'gaps' and 'gluts', and so both the 'at least' phrase and the falsity conditions are redundant in the classical-logic picture. But, again, if one's aim is to accommodate the full space of logical possibilities - and not just those that are relevant to (for example) standard mathematics (governed by classical logic) - then the fuller account of truth and falsity conditions is required.

\footnotetext{
${ }^{19}$ Nullations are included here for completeness (and the symmetry of the boolean quartet) but shall be ignored - because redundant - in what follows.
} 


\subsection{Logic: the target consequence relation}

Finally, the target relation - namely, logical consequence - may be specified in terms of the given FDE models and truth/falsity conditions. The consequence relation is a relation between a set of sentences $X$ and a sentence $A$. The definition is this:

- $\quad X$ logically entails $A$ (equivalently: $A$ is a logical consequence of $X$ ) iff there is no model in which everything in $X$ is at least true but $A$ is not even at least true.

When $X$ logically entails $A$ we say that the argument from $X$ to $A$ is logically valid that is, valid by logic's lights. We use $\vdash$ to represent the logical consequence relation, sometimes writing ' $X \vdash A$ ' as shorthand for the claim that $X$ logically entails $A$ according to the given (FDE) consequence relation. ${ }^{20}$

Some key invalid argument forms, relevant to the project of Contradictory Christology (and also other non-theological phenomena) are these, where ' $X \forall A$ ' indicates that $X$ does not logically entail $A$ :

- $\quad A \wedge \neg A \Vdash B$. (Hence, as far as logic is concerned, a theory can contain a contradiction $A \wedge \neg A$ without thereby entailing all sentences whatsoever.)

- $\quad B \Vdash A \vee \neg A$. (Hence, a theory is not required by logic alone to contain all instances of the so-called law of excluded middle - a principle that may well be in force for some important theory-specific consequence relations, but isn't required by logic itself.)

On the other hand, all standard De Morgan interaction between logical expressions remains in force as the chief concern of logic. For example, where $\dashv \vdash$ indicates logical equivalence (i.e., two-way logical entailment):

$\begin{array}{ll}\text { - } & \neg(A \wedge B) \dashv \vdash \neg A \vee \neg B . \\ \text { - } & \neg(A \vee B) \dashv \vdash \neg A \wedge \neg B . \\ & \neg A \dashv \vdash+A \dashv \text { } A .\end{array}$

In effect, the FDE picture is one in which logic demands De Morgan interaction among the logical expressions, but that is all that logic itself demands. The harder question of whether atomic sentences are 'gappy' or 'glutty' is a theory-specific matter for the given phenomenon; logic itself recognizes possibilities in which atomic sentences take on any of the four (logically possible) semantic statuses.

\footnotetext{
${ }^{20}$ When the set $X$ contains exactly one sentence $B$ we shall write ' $B \vdash A$ ' instead of the explicit $\{B\} \vdash$ $A$. Similarly, when the set $X$ is empty we shall write ' $\vdash A$ ' instead of the more explicit ' $\varnothing \vdash A$ '. (This notation is not central for present purposes but is useful to have at hand.)
} 


\subsubsection{Chief virtues of this account of logic}

There are at least three salient virtues of this (FDE) account of logic.

The first virtue is that the familiar truth/falsity conditions are maintained, as above. There is no revision of the truth/falsity conditions; there is instead a more complete and explicit account. In this way, the 'meanings' of the standard logical vocabulary remain as per the standard (classical-logic) account; it's just that the former account is to be seen as in fact a restricted account: it is a theory-specific consequence relation (e.g., for mathematical theories) that restricts its truth and falsity conditions only to the logical possibilities in which 'exclusion' and 'exhaustion' are satisfied. There is nothing at all wrong with the resulting consequence relation on such a restriction; it's just that, as above, the full space of logical possibilities demands a fuller and explicit specification of truth/falsity conditions - namely, the ones involved in the given (FDE) account.

A second virtue is that the resulting logic is clearly topic-neutral by not taking a stand on whether gappy or glutty atomic sentences are ruled out. Such an issue, as far as logic is concerned, is a topic-central one for theories to figure out. This is a virtue for an account of logic itself; it is a frustration for the epistemological process of determining the true theory of various phenomena, but that's a different matter. Epistemology (or rational 'change in view') is a complicated but distinct discipline from a theory of logical consequence (see Beall 2015; Harman 1986).

A third virtue is most relevant to the principal project of a Contradictory Christology: namely, that logic does not force unique, strange phenomena into the cramped confines of classical-logic possibilities. While logic itself is silent on whether theorists should entertain a contradictory (glutty) theory of a given phenomenon or, similarly, a gappy one, or an entirely 'classical-logic' theory - logic itself, contrary to the standard account, doesn't rule it out. And in the face of extraordinary or strikingly bizarre phenomena it is a good thing to have a very wide space of possibilities to work with in constructing a true theory of the rare entity.

\section{Contradictory Christology}

It should now be plain that a Contradictory Christology is not ruled out by logic itself. One must now ask why it should be ruled out. By my lights, it should not.

I claim that a Contradictory Christology - and negation-inconsistent theology in general - is viable. In particular, the key, fundamental thesis of orthodox Christology is that Christ has two - apparently contradictory - natures. The fundamental problem for Christology is to respond to the apparent contradiction. While many sophisticated theories have spelled out ways to conceive of the apparent contradiction of Christ as non-contradictory, few have argued against the position being advanced here: namely, that the true Christology is in fact logically contradictory, just as it appears to be. ${ }^{21}$

${ }^{21}$ There are some who have argued against the very idea of a glutty theology, including Timothy Pawl (2015) and John Anderson (2007). I discuss some of their arguments in §5. While I do not think that 


\subsection{Christ as the fundamental 'problem'}

The fundamental problem of Christology is simple to see. The apparent contradiction is glaring; one needn't be steeped in the conciliar texts or theological tomes to be confronted by it.

Orthodox Christianity maintains that Christ is the divine, omniscient God who also exemplifies non-divine human nature with its imperfect knowledge and imperfect understanding. The apparent contradiction is vivid, fueled by the foundational role of Christ in orthodox Christianity. An omniscient being could not have our imperfect understanding of the pains and frustrations of our limited epistemic states unless - and here is the problem in a nutshell - the being were not omniscient. The apparent contradiction fuels the pull of the Kenotic tradition in Christology which, against orthodox Christianity (my focus here), puts priority on exactly one of the two natures. The pull of Kenotic Christology arises from the simple contradiction of Christ's needing to be imperfect in his understanding and knowledge in order to have the experience of imperfect epistemic agents; but to be worthy of worship Christ needs to be divine and perfect in his understanding and knowledge. The fundamental 'problem' of Christology is simple to see from the role that Christ occupies: the Christ figure is to have the divine properties of God who is worthy of worship but is to have the logical complement of those properties. (Contradiction.) The way that this is achieved - the way that Christ realizes the apparently contradictory role - is exactly as orthodoxy seems to imply: the having of two contradictory natures, the one divine and the other human. The Conciliar texts use language like 'passible and impassible' and 'capable of suffering and incapable of suffering' (Tanner 1990, 162), but the explicit contradiction comes from standard paraphrases of 'incapable of suffering' as 'not capable of suffering'. ${ }^{22}$

\footnotetext{
his project is (at all) in line with Contradictory Christology as I advance it here, John Dahms (1978) deserves credit for being the first contemporary theologian to advocate something gesturing in the area of a glut-theoretic Christian theology, even though the view he actually advocates is not clear to me in the end - including whether he holds that the true Christian theology is a (closed) negationinconsistent theory. While deserving credit for questioning the standard account of logic, Dahms' work is nonetheless very different in both detail and even broad strokes from the position I advocate in the current paper. One (among many) critical and salient difference(s) is that Dahms' conception of logic is at odds with what I take to be essential to logic - namely, its universality (and, for that matter, topicneutrality). Complicating matters is that Dahms' work hints at theology's being entirely free from logic, a position he fails to elucidate, and a position that I do not understand if, as I take it, theology is a truthseeking discipline. Still, despite its not clearly being a precedent for a serious glut-theoretic theology, Dahms' work deserves credit for looking in what I take to be the right direction.

Aaron (A. J.) Cotnoir (2017) also deserves credit for advocating the exploration of gluttheoretic Christian theology. Cotnoir's work is an initial, partial exploration of different glut-theoretic options - some compatible with the position advanced here, some not. I intend to discuss Cotnoir's results in the larger project of which this paper is a part.

22 Timothy Pawl's recent contribution to the fundamental problem of Christology seeks to avoid the apparent contradiction by redoing the natural truth conditions - or satisfaction conditions - of predicates such as 'incapable' and 'impassible'. The view is one against which my current proposal must ultimately be weighed, but I leave that for later work. The aim at the moment is simply to defend the viability of a simple and (by my lights) natural Contradictory Christology. [I do agree with much of Pawl's work. A major disagreement is the correct account of logic itself (Pawl thinks that it's largely
} 
On the Christology being proposed Christ plays the foundational role of both having the features required to fully experience suffering as we experience it while at the exact same time being worthy of worship and incapable - not capable - of such suffering or imperfect understanding of such suffering. The contradiction of Christ, on the proposed Christology, is not there because the Conciliar-text authors were sloppy; it's there because Christ's foundational role in Christianity requires something contradictory - and thereby something extraordinary, unique and awesome. Of course, if logic itself required that a contradiction - the logical conjunction of a sentence and its logical negation - entails outright absurdity, then Contradictory Christology would be absurd and immediately off the table. But logic doesn't rule it out. (Recall that $A \wedge \neg A$ does not logically entail arbitrary $B$, unlike in classical logic.) And so the question is whether the apparent contradiction of Christ is motivated. That orthodox Christianity - and the Conciliar texts that at least in large part define it - makes vivid the apparent contradiction of Christ is good reason to think that the apparent contradiction is motivated. ${ }^{23}$

In short, Contradictory Christology responds to the fundamental problem by accepting the apparent contradictions as genuine contradictions. This is not simply 'because we can' (given the correct account of logic); the view is motivated by the screamingly apparent contradiction at the heart of Christ's role - perfect God but also as human in imperfection and limitation as you and me. On a mistaken view of logic the proposed solution to the fundamental problem would be off the table. But we need not carry a mistaken view of logic. And once dropped we may fully explore the logical possibility of embracing the contradiction of Christ at face value.

\subsection{The rarity of true contradictory theories}

Before addressing a number of objections, which aim to fill out the proposal further, a very common reaction should be addressed: I am not hereby proposing that theologians should seek to find contradictions willy nilly. The reason that we generally reject all logical contradictions is that true ones are ultimately few and far between. And this is why so few of our true theories are contradictory (i.e., negationinconsistent). Logically possible contradictions are nonetheless ruled out in many theories as theoretically impossible, given the nature of the theory's target phenomenon. Standard mathematics rules out - or blocks off - the logical possibility of contradictions as mathematically impossible; and much of physical theory, biological theory, many metaphysical theories do the same. But in strange cases of extraordinary phenomena the truth may require a contradiction.

My proposal, again, is not that theologians ought to seek out contradictions; the proposal is that Christ's unique role motivates a contradictory account - his contradictory exemplification of two complementary (contradiction-entailing)

standard while, as above, I think that it is weaker than the standard account), though we are, I think, in agreement about the role of logic (qua logical entailment) in theology.]

${ }^{23}$ Pawl 2014 gives a hermeneutical (charity-driven) argument against Contradictory Christology. I take this up in the objections-replies section $§ 5$. 
natures. Having the two complementary natures brings about the truths entailed by having the one and the falsehoods of having the other (and vice versa): Christ is mutable and Christ is not mutable. Said together just so is jarring; but such is Christ's role in the Christian worldview. As a methodological principle, we should not seek out contradictions but we should be open to the rare cases that motivate them. The having of two complementary natures is one case that appears to motivate a contradictory theory (a Contradictory Christology).

Consider an analogy with Truth and Falsity. These are complementary properties in the sense that having them both entails a contradiction. Were there to be some entity that exemplifies both of these properties the entity would be a rare one, something surprising - though perhaps not properly mysterious. As above, I maintain that a very respectable - and, indeed, correct - view of logic is that logic itself does not rule out such an entity, something that is both true and false. Logic enjoys its role of being universal and topic-neutral by being very rich in the possibilities that it recognizes. As it turns out, there are entities - admittedly strange and rare - that (arguably) instantiate or exemplify or have both of the given complementary properties. Witness the familiar Liar paradox: ${ }^{24}$

$\checkmark$ The ticked sentence is false.

This sentence is true if and only if it is false. While (on my view) logic itself won't force the issue, ${ }^{25}$ the ticked sentence is a candidate for the very rare case in which the complementary properties of truth and falsity are exhibited together. As theorists we have a methodological goal of resolving as many claims into the true and the false as possible. Logic, as above, doesn't demand as much; but systematic theorizing motivates the methodological goal. And with that goal, one is quickly motivated to the view that the ticked sentence is false and also true - a contradiction (see Beall 2017).

It is important to emphasize that the ticked sentence is a strange and unexpected case. Moreover, by accepting that the ticked sentence is a (surprising) case of an entity that exemplifies complementary properties we are not thereby committed to accepting that all peculiar sentences are truly contradictory. The very nature of the ticked sentence - a twisted prima facie contradiction - motivates a contradictory theory of it; but few other sentences are like that.

And the same is true of Christ: his role is prima facie contradictory; and his realization of the role via complementary natures reinforces the contradiction. Indeed, when one asks how something could realize a contradiction, orthodox Christology has provided a clear and fascinating answer: namely, the having of two

\footnotetext{
${ }^{24}$ That a true theory of these sorts of peculiar entities (the Liar sentence or similar property/set sentences) might be contradictory is an idea discussed by many, including Asenjo 1966; Asenjo \& Tamburino 1975; Beall 2004; 2009; Dunn 1966; 1976; Priest 1979; 2006; Routley 1979; Routley \& Meyer 1976, and many others, though Priest's work has championed and defended the view more than any other work on the topic. Indeed, Priest's career and large body of work, much like the late Sylvan's (née Routley) career and work, has focused largely on advocating and defending the spread of contradictory theories beyond this limited area.

${ }^{25}$ In order for logic itself to force the issue one needs something like the law of excluded middle, which is not valid according to logic (viz., FDE) as I've advanced it here (see Beall 2017).
} 
complementary natures. In the end, when the truth is laid bare, Christ may be the unique contradictory being in reality. That's for future theorizing to tell. For now, Contradictory Christology affirms the apparently contradictory orthodox Christology as genuinely contradictory. Christ is mutable; Christ is not mutable. It is true that Christ is mutable; it is false that Christ is mutable. This is jarring, and even in some ways mysterious; but orthodox Christianity has advanced the role of Christ to be just so: jarring and in various ways mysterious. In this case, the mystery is (at least in part) that there is a being whose very existence entails contradictions - that he is perfect and all-knowing but is imperfect and has limited knowledge (and so on). Theological traditions - from negative theology to Kenotic theology to the latest analytic-theological proposals - have one and all tried to avoid the logical contradiction of Christ. While I have not argued against those traditions in favor of Contradictory Christology I think that it is plainly as viable an approach to Christology as the others. Future debate will ultimately tell. For now I respond to a number of objections.

\section{Objections and Replies}

\section{0: From some to all contradictions}

Objection: Once we allow some contradictions we have no grounds to reject any contradictions.

Reply. This is simply unmotivated. Consider the directly analogous claim: once we admit that quantum reality is funny we have no grounds to reject that all of reality is funny.

Belaboring the reply (because the objection seems to be very common), consider another analogous claim (familiar to philosophers): once we accept that 'intersubstitutability of identicals' - or 'intersubstitutability of co-referential terms' fails in some (true) theories we have no grounds to accept such intersubstitutability for any (true) theory. Again, this is simply unmotivated. When philosophers discovered (so-called intensional or opaque) contexts (e.g., It is believed that...), contexts in which all of the following are true for some names ' $a$ ' and ' $b$ ' and some predicate ' $F$ ', they were surprised:26

- $\quad a$ is identical to $b$

- It is believed that $a$ is $F$

- $\quad$ It is believed that $b$ is not $F$

But the lesson is not that we now (i.e., post-discovery) have no reason to accept the intersubstitutability of identicals (or co-referential terms) in any theory; the lesson is

\footnotetext{
${ }^{26}$ For a concrete example, replace ' $a$ ' and ' $b$ ' with 'Superman' and 'Clark Kent', respectively, and replace ' $F$ ' with 'flying'. (And to make it doubly concrete, replace the general operator 'it is believed that...' with (for example) 'Lois Lane believes that .....) For many more examples see the (vast) literature on intensional and/or opaque contexts.
} 
simply that there are theories that accommodate peculiar contexts in which intersubstitutability fails. Finding unexpected, abnormal contexts in which intersubstitutability fails does not undermine the importance of such intersubstitutability in many (most) true theories. Of course, we were mistaken if we thought that the principle was logical and hence was thereby demanded across all true theories; but - for all I can see - there is no reason not to demand such intersubstitutability in most of our true theories provided that the discovered (opaque) contexts aren't in play (in the language of the theory). That we have found some contexts (or predicates) - or some phenomena - for which the given intersubstitutability fails gives no reason to reject the principle in (for example) our true theory of arithmetic, physics, or biology.

Contradictory Christology - and Contradictory Christian theology in general is similar. We were mistaken in what we took to be a logical - absolutely universal proscription against true contradictory theories; but for all that I can see the candidates for true contradictory theories remain very rare - indeed, unique if we ignore 'spandrels of truth' (e.g., liar paradoxes, etc.). Of course, maybe the contradiction which is Christ is not unique; maybe there are other such contradictory beings; logic itself doesn't rule them out. But logic rules out precious little; and its failing to rule something out is hardly a good reason to accept it as a leading candidate for truth. Until there's good reason to accept that our true theories of phenomena beyond Christ are likewise glutty I see no reason not to reject the spread of contradictory theories.

\section{1: Historically suspect}

Objection: the proposal is historically suspect. According to Gregory Dunn, Leo the Great maintained that 'Jesus could be both impassible and passible at the same time without there being any contradiction' (Dunn 2001, 81, emphasis mine). ${ }^{27}$ Hence, inasmuch as Dunn's interpretation of Leo is correct, and in turn Leo's texts were ratified as part of orthodox Christology, the proposed Contradictory Christology is historically suspect.

Reply. Distinguish two senses of 'contradiction', one being a sentence which is the logical conjunction of a sentence and its logical negation, and the other being an 'explosive sentence', a sentence that, according to a theory's consequence or entailment relation, entails every sentence (of the language of the theory). The first sense is the one involved in the proposed Contradictory Christology. I agree with Dunn and many others that the true Christology has no true explosive sentences that is, no claims that are both true according to the Christology and also entail all sentences according to the Christology's consequence relation.

\section{2: Hermeneutically suspect}

\footnotetext{
27 This quotation is used by Pawl $(2015,92)$ for different dialectical purposes, but the passage nicely
} frames the current objection. I discuss an importantly related objection, based on Pawl's work, below. 
Objection: the proposal is hermeneutically suspect by being uncharitable in reading conciliar texts. Pawl, focused only on Conciliar Christology (with which my proposal is intended to be compatible), implicitly argues that it's uncharitable to charge the conciliar fathers with advancing a Contradictory Christology: ${ }^{28}$

Had they really believed these five pairs of predicates to be incompatible, they would not have affirmed that Christ is both visible and invisible, incomprehensible and comprehensible, unlimited and limited, impassible and passible, and inexpressible and expressible. It is a rare feat to be able to contradict oneself so forcefully in a single sentence. Any one of these five conjunctive pairs would be enough to entail a contradiction, and the fathers do it five times over! $(2015,64)$

The point is that it's at best uncharitable to interpret the conciliar fathers as advancing anything close to a genuinely contradictory Christology.

Reply. There are two chief problems with Pawl's argument. ${ }^{29}$ The first problem is that Pawl's (charity-driven) hermeneutical argument comes with an uncharitable reading of the conciliar fathers. Either the conciliar fathers used the key predicates (e.g., 'passible' and 'impassible', etc.) in non-standard and yet undefined ways or they used the predicates in their standard ways with their standard but glaringly contradictory consequences. The more charitable reading, as I see the matter, is the latter disjunct. On Pawl's view the conciliar fathers are using the key predicates in a non-standard way. After all, on the standard usage the given pairs of predicates are complementary (in the sense that their joint satisfaction entails a contradiction); and that is logically impossible according to Pawl. But the conciliar fathers are not simply using key terms in a non-standard way; they knowingly left their usage completely undefined. We don't get the special definitions (satisfaction conditions) until Pawl 2016. Why would the conciliar fathers not flag their special - and undefined - usage of (for example) 'incomprehensible' and 'comprehensible' (and 'capable' and 'incapable' and so on) if they didn't intend the usual entailments to hold? Pawl doesn't answer this question but maintains that their usage was indeed non-standard because otherwise the Christology is contradictory. This leads to the second problem with Pawl's argument.

The second problem is that Pawl's argument overlooks the possibility that these 'incompatible' - that is, contradiction-entailing - predicates are precisely what is required for Christ to play the unique role that Christ plays. That Christ must be immutable (entails: not mutable) in order to be worthy of worship while being mutable to experience our suffering (for example) is contradictory; but it's what the conciliar fathers concluded - even if they were not fully clear on how such an extraordinary entity works in detail. If we hold fast to the standard account of logic

\footnotetext{
${ }^{28}$ To be clear, Pawl's arguments are not directed at the Contradictory Christology that I have aimed to defend. His arguments, like much of standard theology, ignores such a Christology. But Pawl's charitydriven hermeneutical argument (below) demands a reply.

${ }^{29}$ I think that Pawl's work on the fundamental problem is very important, and I continue to learn much from it. I intend to do a much more extensive discussion of it vis-a-vis Contradictory Christology in the future. For now, my aim is only to give an initial defense of the viability of Contradictory Christology.
} 
(or any so-called explosive account of logic) then Pawl's hermeneutical argument has force, of course; but I think that that account of logic is misplaced.

\section{3: Implausible}

Objection: accepting that Christ exemplified a property and its logical complement is downright implausible. As such the proposed Contradictory Christology is implausible.

Reply. If the objection is an empirical claim about what human believers can in fact believe then the objection needs to be evaluated empirically. But there are philosophers who in fact believe of various entities that they instantiate a property and the property's logical complement. Pending further empirical tests such philosophers appear to be counterexamples to the sort of empirical charge of implausibility advanced in the objection.

But perhaps 'implausible' is used in a weaker sense: it's hard to believe; it's nearly incredible (nearly not believable), and so on. But in this case, such a property is to be expected of the true Christology. After all, the true story of Christ - the true story of the extraordinary GodMan - is nearly beyond belief. That Christian theologians of all stripes have emphasized the necessity of faith in the face of 'implausibility' is not an objection to the truth; it's (at least in part) a recognition of the implausibility of the truth.

\section{4: Ad hoc}

Objection: the proposal is ad hoc. The fundamental problem of Christology is a difficult one to solve. The proposal points to an alternative logic that can handle contradictions without reducing a theory to all-out absurdity; and then the proposal simply hitches the logic to Christology without independent motivation.

Reply. This objection is misplaced on two fronts. To begin, the alternative (subclassical) account of logic has been motivated in the philosophy of logic by a wide range of theology-independent phenomena, from concerns peculiar to 'relevance' of logic (see Anderson and Belnap 1975; Anderson, Belnap, and Dunn 1992) to modeling various inconsistent but not flat-out absurd theories (e.g., so-called naive account of sets or properties) to strange phenomena from language (e.g., paradoxes - see Priest 2000). So, the given logic itself is not ad hoc.

The second front on which the objection is misplaced is the charge specific to Christology, namely, that Contradictory Christology is an ad hoc solution to the fundamental problem. But this is simply wrong. The very conciliar texts that at least in part define orthodox Christianity carry the prima facie contradiction of Christ on their jackets. That the true Christology is in fact logically contradictory is a natural response to the fundamental problem; it has been long ignored simply because of a restricted account of logic.

\section{5: Truth requires coherence}


Objection: ${ }^{30}$ Coherence is a necessary condition for truth, and a coherent Christology rules out Contradictory Christology - since a true list of Christ's properties cannot contain contradictory pairs (see Cross 2011, 480).

Reply. Setting aside epistemic and question-begging accounts of 'coherence' (as, respectively, irrelevant and uncharitable) the objection rests on a true principle: namely, that true theories must 'hang together' in a way that avoids outright triviality, where triviality is the uncontroversially absurd 'trivial theory' - namely, the theory containing all sentences in the language of the theory. ${ }^{31}$ On the standard view of logic no logically contradictory theory can 'hang together' (cohere) in the given way, since logic itself - on the standard view - takes every logically contradictory theory to the trivial theory. But that view of logic is not forced on theology; a more natural account of logic is in the (so-called subclassical) vicinity of FDE. While true theories demand coherence, a logically contradictory theory can be coherent, contrary to the objection's presupposition.

\section{6: Other theological contradictions}

Objection: it looks like the proposed Christology naturally generalizes to other parts of theology. In particular, doesn't the general proposal require that every apparent contradiction in theology be treated as contradictory - including, perhaps especially, the very familiar 'logical' puzzles involving God's omniscience, omnipotence (a tooheavy stone) and the like?

Reply. No. While logic leaves open such possibilities - and theologians should be aware of such logical possibilities - the contradiction needs to be motivated too. While the familiar 'logical' problems of orthodox Christianity's 'omnigod' are candidates for a contradictory proposal, the contradiction involved is not as clear in (for example) conciliar sources as the screamingly apparent contradiction of Christ's role and two natures. I do not rule out a contradictory resolution of other theological problems but, pending debate, my proposal is restricted to the fundamental problem of Christology. ${ }^{32}$

\footnotetext{
${ }^{30}$ This objection is in the spirit of leading work on Christology. While he is not focused on Contradictory Christology in the relevant passage (see below), I frame the current objection in terms drawn from Richard Cross's state-of-the-art discussion of the fundamental problem (see Cross 2011, 480).

${ }^{31}$ For example, the standard (say) theory of arithmetic (say, Peano Arithmetic) is written in a certain language, namely, the language of the theory; and the trivial theory of arithmetic, relative to that language, is the theory that contains all sentences of the language. (There is absolutely nothing special about arithmetic. It's used here as a very simple example of the term 'trivial theory' as it occurs in contemporary philosophy of logic.)

32 For what it is worth my own view is that many such familiar 'logical' problems motivate a 'gappy' (vs 'glutty') theology - for example, where certain claims are neither true nor false - but this is for another occasion. See Beall \& Cotnoir's work on the stone problem (2017) as an example of a gappy theology which is perfectly compatible with the FDE-logic-based theology advanced here. Moreover, my own view of apparent Trinitarian contradictions is to rely on non-transitive identity - a theologyspecific account of identity that isn't ruled out by logic (since, on my view, logic itself is neutral on identity). But these issues are for a much bigger project. I mention them here only to illustrate that the
} 


\section{7: Heretical}

Objection: Your position is heretical in that your theory has heretical claims as consequences. ${ }^{33}$ You maintain that Christ's divine nature entails Christ's impassibility:

(1) That Christ is divine entails that Christ is impassible.

(1) together with similar entailments give rise to the fundamental 'problem' of Christology. The trouble is that entailment contraposes, that is,

(2) If $A$ entails $B$ then $\neg B$ entails $\neg A$.

Hence, from (1) and (2), we have (3) as a consequence, namely:

(3) That Christ is passible entails that Christ is not divine.

But, now, since your theory affirms (the orthodox, Chalcedonian claim) that Christ is passible we get from (3) the heretical (4):

(4) Christ is not divine.

This is plainly heretical. And the same argument goes through to show that your theory claims other heresies - such as that Christ is not human. Inasmuch as your Contradictory Christology aims to be compatible with at least the spirit of Chalcedoninspired Christology, the current objection shows that Contradictory Christology fails, and should therefore be rejected. ${ }^{34}$

proposed Contradictory Christology is not wedded to gluts (truth-value gluts) at every theological turn; logic also affords gaps as possibilities.

For a general exploration of glut-theoretic options on 'logical' problems in theology, see Cotnoir 2017.

33 Dave Ripley pushed this objection at a UNAM Conference in Mexico. The objection is a more direct version of an objection by James Anderson $(2007,125 \mathrm{ff}$ ), namely, Anderson's third (and, by his lights, weightiest) objection against a glut-theoretic theology. I treat the other two of Anderson's three objections in separate objections below; I discuss his version of the current objection in footnote 34 below.

${ }^{34}$ As above, an objection by James Anderson, which is of a kind with the current objection, is that Contradictory Christology winds up making the preservation of orthodoxy irrelevant because it is (allegedly) forced to make heretical claims (see Anderson 2007, 125ff). Anderson's exact objection points to identity claims that, he alleges, would arise from a glutty approach to the Trinity (about which I've said nothing here, but in the bigger project will discuss). By my lights this is a bad example; it's a hard task for any theory to come up with the right identity relation, and perhaps especially so for Christian theology, and especially as involving doctrines of the Trinity. But one thing is pretty clear: either identity in Christian theology (especially the relation involved in the Trinity) will not be transitive or it will invalidate the sort of substitution principles on which Anderson's objection relies. Anderson just assumes that either it is transitive or it allows for familiar substitution (or both). (He might be thinking that logic itself has an identity predicate, and so, inasmuch as logical vocabulary is universal and part of every theory, that predicate is involved in Christian theology. That logic has an 
Reply. There are two important parts of the reply. The first part of the reply is to note that heresies need to be understood in a way compatible with the possibility of Contradictory Christology. In particular, a familiar heresy concerning Christ's divinity may be understood in at least two ways:

- $\quad$ Presence of Negation: the theory contains the given negation (viz., 'It's false that Christ is divine').

- $\quad$ Absence of Nullation: the theory fails to contain the given 'nullation' (viz., 'It is true that Christ is divine').

The current objection charges that Contradictory Christology, as advanced here, commits a heresy in the $\mathrm{H} 1$ sense; but there is no suggestion that the theory commits a heresy in the $\mathrm{H} 2$ sense. By my lights, it would not be surprising were the truth of Christ, who is the unique contradictory being at the center of Christian theology, to involve 'heresies' in the H1 sense. After all, that Christ exemplifies two complementary natures (the joint satisfaction of which entails a contradiction) may bring about falsity claims that appear to be deeply heretical (i.e., H1-heretical); but the substantial heresies, at least by my lights, involve an outright rejection of the orthodox claims - the absence of such claims from our Christology. The substance of serious heresy is in H2: namely, having a theory that rejects or omits the given truth (e.g., that Christ is divine, that Christ is human, etc.).

The second part of the reply is to refute the claim that Contradictory Christology, as advanced here, commits a heresy even in the H1 sense. What the objection assumes is that our Christology's consequence relation - our entailment relation for our theory of Christ - contraposes. This assumption is erroneous. Indeed, the objection illustrates precisely why the entailment relation for true Christology fails to contrapose.

It is true that logical entailment (viz., FDE, as outlined above) contraposes: if the entailment relation in premiss (2) of the objection concerns only logical entailment, then premiss (2) is correct. But if premiss (2) is talking about logical entailment, then - for the objection's argument to work - premiss (1) is also talking about logical entailment. But (1) should be rejected if it is talking about logical entailment, since logic is completely neutral on things like passibility and human natures; such things are beyond the sparse, topic-neutral logical vocabulary. If (1) is true - and it is true - then (1) is not talking about logical entailment; it's talking about the entailment (or consequence) relation involved in our specific theological theory. And there's no reason to think that that relation contraposes. (Indeed, as above, there's reason - in the objection - to think that it doesn't.)

identity predicate is incorrect, as I see things; logic does not have an identity predicate (identity relations are not topic-neutral enough to be logical), and even if it did it would hardly be even an equivalence relation. Moreover, even if, contrary to what I think is the correct account, logic had an identity predicate there's no reason to think that that predicate is the one involved in expressing the axiomatic truths of the Trinity. But I leave these issues for another venue.) 


\section{8: Awkward consequence}

Objection: James Anderson gives various objections to a would-be glutty theology (i.e., a theology with at least 'truth-value gluts' about God). ${ }^{35}$ The first is crisp and powerful:

[Your Contradictory Christology] has the odd consequence that God believes some falsehoods (about God, no less) and invites us to do likewise. This criticism may not be decisive, but it seems hard to reconcile this outcome with the biblical emphasis on promoting truth and eschewing untruth (e.g., Ps. 52:3; Eph. 4:25; 1 John 4:6). (2007, 125)

Anderson is right: your glutty theology is both awkward and, more problematic, goes against Scripture.

Reply. The objection is not only not decisive; it simply repeats the core thesis of Contradictory Christology, namely, that the full truth of Christ involves falsehoods. If by 'odd consequence' is meant a surprising, unfamiliar, and strange consequence, then I am in agreement with the claim that Contradictory Christology has the given odd consequence. But this is not an objection. After all, all theologians agree that Christ's very being is surprising, unfamiliar and very strange - if shown by nothing else than the fundamental problem of Christ's being.

God is omniscient. God knows the full truth of Christ. Since the full truth of Christ involves falsehoods (e.g., 'Christ is mutable', etc.) then some of God's knowledge is knowledge of falsehoods - which, of course, are also truths (since knowledge demands truth). True falsehoods are so rare as to make them strange, surprising and very unfamiliar; and their existence comes about only in the strangest, most surprising cases - such as Christ.

Does this position go against Scripture's promotion of seeking truth and avoiding falsehood? No. Seeking truth is paramount; and falsehood is to be avoided at all costs short of losing truth. Scripture's dictate concerns the normal situation wherein truth and falsity are not inextricably bound together as they are in the unique case of Christ. In the case of Christ we pursue the full truth; and with it we wind up with falsehoods which are also true. Such is Christ's unique being. ${ }^{36}$

\footnotetext{
${ }^{35}$ Anderson uses the now-not-uncommon term 'dialetheism' (sometimes 'dialethism', with adjective 'dialetheic' or 'dialethic') for any glut theory - that is, a theory that contains gluts (i.e., true falsehoods). Instead of that terminology I mostly use 'Contradictory Christology' to make Anderson's objection specific to my proposal.

On broader terminology: I prefer the simpler terminology of 'glut theory' (with adjective 'glutty'), which is the dual of 'gap theory' (with adjective 'gappy'); this simpler terminology predates the neologism 'dialetheism'. (Some glut theorists - including Graham Priest and Richard Sylvan (née Routley) who coined the term 'dialetheism' ('dialethism') - prefer the later terminology because they think that 'glut' carries negative connotations. I do not share such a view.)

${ }^{36}$ Also - lest there by any doubt - it's worth noting that the Scriptural texts which Anderson's objection highlights concern lying and deception (vs falsity on its own); and there is no part of Contradictory Christology that advocates lying or deception.
} 


\section{9: Phenomenological support}

Objection: James Anderson gives another objection to Contradictory Christology (and glutty theology generally), one that he takes to be as 'weighty' as the first:

[T] he law of non-contradiction enjoys considerable prima facie support by way of the phenomenology and ubiquity of belief in it. If nothing else, this indicates that a rejection of the law should serve only as a last resort in attempting to address the [fundamental problem]. Moreover, [a glutty] solution is likely to endear itself only to those standing within the Christian faith (and even then will be deemed a bitter pill). As a defensive strategy to counter the charge of irrationality levelled at Christian doctrines, it lacks plausibility and smacks of special pleading $(2007,125)$.

Reply. There are (again) many things that can be said by way of reply. I limit the reply to comments on four strands of the objection: 'the law of non-contradiction', the relevance of phenomenology to logic, the apparent ubiquity of said 'law', and the issue of defending Christian theory against charges of irrationality.

Non-contradiction. The term 'the law of non-contradiction' is notoriously ambiguous, as the philosophy of logic has made plain (see Priest et al. 2004). On one hand, one might think that the law is a logically true sentence, something like the logical conjunction of a sentence and its logical negation is false, which is standardly symbolized

$\neg(A \wedge \neg A)$

where $A$ is any sentence in the language of one's theory. But to express the logical truth of such a thing one uses the logical consequence relation (here symbolized as a single turnstile), namely:

$$
\vdash \neg(A \wedge \neg A)
$$

This is a top candidate for 'the' law of non-contradiction, but this can't be what Anderson (or others) have in mind, since this is compatible with glut theory. ${ }^{37}$

Another candidate is some sort of extra-logical principle about rational acceptance and rejection, namely, that one ought (rationally) to reject all contradictions, where a contradiction, as throughout, is the logical conjunction of a sentence and its logical negation. Of course, this is an exceedingly difficult principle to justify in the face of viable glut theories, especially if some of those glut theories are true - such as, as I have suggested, Contradictory Christology. At the very least, this sort of 'law of non-contradiction' - which concerns the thorny area of rational

37 The scheme is not logically true in FDE, which I take to be the right account of logic; but even if it were logically true, as it is in a well-known extension of FDE called 'LP' (see Asenjo 1966; Priest 1979), its logical truth wouldn't rule out the logical possibility of $A \wedge \neg A$ also being true for some $A$. 
'change in view' (see Beall 2015; Harman 1986) - is question-begging if launched against the viability of Contradictory Christology. This too is not what I think is the central notion of non-contradiction.

The core notion of non-contradiction at issue for Contradictory Christology is a version that is directly incompatible with Contradictory Christology. This version of non-contradiction, on which I henceforth take the current objection to focus, is sometimes called 'ex contradictione quodlibet' or, with more flair, 'explosion' (the latter colorfully indicating that a jot of negation inconsistency explodes a theory into the absurd trivial theory, which is the theory that contains all sentences of the language of the theory):

$$
A, \neg A \vdash B
$$

where $A$ and $B$ are any sentences of the given language, and $\vdash$ is logical consequence (and, hence, is part of every consequence relation involved in any of our theories). In what follows I shall take the objection to concern this 'law' - better described as a 'rule' - of non-contradiction: namely, that arbitrary $A$ together with its logical negation $\neg A$ (and, hence, by logic, the contradiction $A \wedge \neg A$ ) logically entails $B$. Contradictory Christology rejects this 'law', and must do so on pain of a simply absurd Christology - the trivial Christology.

Phenomenology of explosion. The objection alleges that there is strong phenomenological support for non-contradiction. I question whether this is true. (Does it 'feel right' that 'Satan is a Christian' logically follows from the claim that Christ is passible and impassible - or, more explicitly, that Christ is passible and yet Christ is not passible?) Even if the phenomenological feel supports explosion as a logical principle, the methodology of following phenomenology in this context is unmotivated. After all, logical consequence governs all cases whatsoever; logic is topic-neutral, universal, and is not at all subject to a particular corner of reality. But phenomenology is notorious for being a product of parochial diets: your 'phenomenological feel' depends on what you've eaten (so to speak). Indeed, that non-contradiction, understood as above (viz., explosion), is entrenched in a standard account of logic (viz., so-called classical logic) is not surprising; the standard account of logic was built exclusively on the diet of (classical) mathematics - a key topic for philosophical reflection. But phenomena like vagueness, semantic or 'logical' paradoxes, let alone phenomena like the unique Christ, were not even on the table when the standard account was crafted. Trusting phenomenology to determine logical consequence is not a reliable strategy.

Apparent ubiquity of 'explosion'. The objection points out that explosion (as the relevant 'law' of non-contradiction) is apparently ubiquitous in our best theories. (The objection talks about 'ubiquity of belief in it', but it is clearer to talk in this context of its role in our best theories - which, presumably, reflect our beliefs, etc.) On this point the objection is clearly right: explosion looks to play a dominant role in many - perhaps most - of our theories. So, how do we explain the apparent ubiquity of explosion in our theories if explosion is to be rejected?

Here, we need (as always) to distinguish logical consequence (represented as the bare single turnstile above) from a given theory's consequence relation. 
Explosion, as a logical rule (using logical consequence), is rejected by all viable glut theories, and certainly by Contradictory Christology. But this does not mean that our theory-specific consequence relations do not exhibit explosion.

The topic is too big for this paper but the point, in short, is simply that theoryspecific consequence relations (say, $\vdash_{T}$, for some theory T), while building on top of logic (and so not transgressing logic in any way), often build a form of explosion into the theory. For example, in our true theory of arithmetic, logic itself (qua FDE, as above) does not demand explosion; it says that it's logically invalid. But arithmetic's consequence relation $\vdash_{T}$ builds in explosion by narrowing the class of logical possibilities down to the ones that the theory takes to be (theoretically) possible. In particular, the theory (unlike logic) rules out the possibility of gluts for any predicates involved in arithmetic by enforcing this condition:

$$
\exists x(F x \wedge \neg F x) \vdash_{T} \perp
$$

where ' $\exists x$ ' stands for logic's 'there exists at least one $x$ such that' and ' $F x$ ' is an open sentence ('property' or predicate) of the language of arithmetic, and $\perp$ is a sentence that entails, according to the theory's consequence relation, all sentences of the theory. ${ }^{38}$ The effect of this condition is to narrow the set of theoretical possibilities down to exactly two sorts: the trivial one (where everything is true) and non-glutty ones (ones where no contradiction is true). With such a restriction on every predicate in the language of the theory one can show that any model of the theory is either trivial or negation-consistent - which is all that classical-logic theories can achieve. While there is a lot more that can be said on the ubiquity of 'explosion' in many of our best theories, this is not the place; however, enough has been said to indicate that the apparent (and, I agree, genuine) ubiquity of explosive consequence relations is compatible with the failure of explosion in logic and, in particular, in Christology. ${ }^{39}$

Defending Christian theory against charges of irrationality. The objection points out that if the aim of a solution to the fundamental problem is to defend Christian theology against the charge of irrationality (which is James Anderson's key aim in his given book) then Contradictory Christology - or any other glut-theoretic theology - is not likely to be a front-running candidate, since the charge of irrationality is likely to come from those who assume (erroneously) that rationality demands non-contradictory theories.

The objection, as I see things, is irrelevant to the viability of Contradictory Christology. The aim of Christology is to give the truth of Christ. The heart of Contradictory Christology is that the truth of Christ is contradictory. If one charges that that - the contradiction - is irrational, then let the objector state her grounds for saying as much. I have little doubt that the objector's 'grounds' will ultimately point to the standard account of logic, and also point to principles tying the given account of logic to (a theory of) rational acceptance-rejection behavior. While these are difficult matters to adjudicate, there is enough work in the philosophy of logic (and

\footnotetext{
${ }^{38}$ I use a unary predicate for simplicity; the generalization to any finite arity is straightforward.

39 For a lot more on how explosive consequence relations play important roles in our theories despite logic's failure to be explosive, see work on 'shrieking' (e.g., Beall 2013a; 2013b; 2015).
} 
theories of rational acceptance-rejection behavior) to question the strength of such planks in the objector's charge.

My aim is not to win debate; my aim is to get at the truth. And when it comes down to it, I find it very difficult to see how the standard account of logic can be the right account given the existence of bizarre phenomena like Christ - or of lesser, theology-independent entities like common paradoxical phenomena. But if logic itself doesn't rule out the gluttiness of such entities then an argument is required for the view that something else does; but pending such an argument the view remains highly viable, by my lights.

\section{0: Just highfalutin theory}

Objection: This is all just highfalutin theory; it has nothing to do with the real work of Christology or theology in general.

Reply. That's just wrong. Theologians are theoreticians who, if aiming to get at the true theory of God, seek to record not only the fundamental truths but also all consequences of those truths. And this requires that theologians construct an appropriate consequence (closure) relation for theology. And to do this the theologian must take a stance on the fundamental closure relation: namely, logic itself. To think that it's obvious that logic is as per the standard account of logic (viz., so-called classical) is to think in error. Even defenders of the standard account of logic reject that it's obvious that logic is per the standard account.

Moreover, there is a genuine practical upside to Contradictory Christology. The role of Christ demands an entity who is not unlimited, one who can truly understand and experience our limited and imperfect ignorance of what it would be like to escape limitations (something we can only imperfectly imagine); but the role of Christ equally demands an entity who is devoid of limitations - the perfect and limitless God worthy of worship by all. The fundamental 'problem' of Christology is that this role is contradictory; it demands realization at the price of a contradictory being. But Christians may rest assured that Christ is that contradiction: truly perfect; truly imperfect - all in the standard senses of those terms. Hiding the full force of Christ's contradictory being by trying to block the full contradictory consequences that follow from it is to hide the full spectrum of properties that Christ exemplifies and that Christians need Christ to exemplify. A full understanding of Christ's contradictory being may be beyond our currently limited epistemic reach; but Christ's reality - by all orthodox lights - is not in any way constrained by our epistemic reach.

\section{1: Not theology}

Objection: The proposed theory is not theology. Theologians need not master the technical tools of contemporary logic in order to give a true theory of Christ - a true Christology - or a true theory of any other theological phenomenon. But your 
proposed theory - the proposed Contradictory Christology - requires a mastery of just such technical logic.40

Reply. A full-on mastery of logic is not required; but basic competence in logic and its role is required. The viability of any Christology - not just that of Contradictory Christology - relies on logic itself, on the logical consequence relation at the bottom of all consequence relations for our true theories (including our true theory of God). Of course, that theology is not about logic is absolutely clear and equally true. But theology needn't be about logic in order for logic to be of fundamental importance in the true theology. Theology relies on logic; and theologians need to be aware of logic's constraints - and, more to the present paper, logic's space of possibilities.

\section{Towards future theology}

Part of one's task as a theologian is to record theological truth. Treating various claims as axiomatic or basic or bedrock is the beginning. More work arises in constructing a consequence relation for theology - a relation that 'completes' the theory by delivering the consequences of the theory. Any such consequence relation needs to be in step with logic itself - the foundational consequence relation of all of our true theories. Contemporary philosophy of logic has provided good reason to think that logic is subclassical - properly weaker than standard (so-called classical) logic. This has direct effects on the space of theological options.

In this paper I have sketched one new option for Christology. What is important to emphasize is that the proposal is not an unmotivated hack brought about as an ad hoc patch in theology. Logic is different from what many theologians believe. And the truth of Christ may, accordingly, be very different from what most theologians believe too; the truth may be as logically contradictory as the fundamental 'problem' paints. My hope is that this paper puts Contradictory Christology on the theological table. Debate must now measure its promise against the other proposed solutions.

This paper is part of a larger project that aims to measure Contradictory Christology against standard accounts (including, but not limited to, the many 'qua' accounts, 'mereological' accounts, 'negative-theological' accounts, and more). The larger project aims not only to spell out the proposed Contradictory Christology further; it aims to argue directly for the position vis-a-vis limitations of standard accounts. But that remains for a larger project. This paper, as above, has the aim of defending a place at the table for Contradictory Christology. ${ }^{41}$

\footnotetext{
40 Compare debates over the importance of analytic theology (see Crisp and Rea 2009).

${ }^{41}$ Acknowledgements: As may be evident throughout, I've benefited a great deal from Timothy Pawl's recent work on the fundamental problem of Christology. Conversations with Gill Russell, Daniel Nolan, Susana Gómez and John Troyer helped clarify my thinking on early drafts. I am also grateful to Dave Ripley for ongoing conversation about this (and many other) topic(s), and similarly to Jared Henderson whose feedback and insights have been invaluable. The Institute for Philosophy at UNAM (Mexico) hosted a lively (and controversial) colloquium on this paper, and the logicians and philosophers who participated (including The Trivial One) provided valuable feedback. Trent Dougherty also provided feedback on the penultimate version of this paper. I am very grateful to Mike Rea and Sam Newlands
} 


\section{Bibliography}

Adams, Marilyn McCord. 2006. Christ and Horrors: The Coherence of Christology. Cambridge University Press.

Anderson, Alan Ross and Nuel D. Belnap. 1975. Entailment: The Logic of Relevance and Necessity. Vol. 1. Princeton University Press.

Anderson, Alan Ross, Nuel D. Belnap, and J. Michael Dunn. 1992. Entailment: The Logic of Relevance and Necessity. Vol. 2. Princeton University Press.

Anderson, James. 2007. Paradoxes in Christian Theology. Paternoster Press.

Asenjo, F. G. 1966. "A calculus of antinomies." Notre Dame Journal of Formal Logic 7 (1): 103-105.

Asenjo, F. G. and J. Tamburino. 1975. Logic of antinomies. Notre Dame Journal of Formal Logic 16 (1): 17-44.

Bäck, Allan. 1982. “Aquinas on the incarnation.” New Scholasticism 56 (2): 127- 145.

Beall, Jc. 2004. "True and false-as if." In The Law of Non-Contradiction, edited by Graham Priest, Jc Beall, and B. Armour-Garb. Oxford University Press. 2009. Spandrels of Truth. Oxford University Press. . 2013a. "LP+ $\mathrm{K3}^{+}, \mathrm{FDE}^{+}$and their classical collapse." Review of Symbolic Logic 6 (4): 742-754.

. 2013b. "A simple approach towards recapturing consistent theories in paraconsistent settings." Review of Symbolic Logic 6 (4): 755-764.

. 2015 "Free of detachment: Logic, rationality, and gluts." Noûs 49 (2): 410423.

. 2017. "There is no logical negation: true, false, both and neither." In Nonclassicality: logic, philosophy, and mathematics, edited by Patrick Girarad and Zach Weber. Australasian Journal of Logic.

for hosting a lively - and very, very helpful - forum on this paper at the Notre Dame Center for Philosophy of Religion, and to all of the philosophers and theologians who participated in that forum. Finally, I am especially grateful to Aaron Cotnoir with whom I have had many conversations over (too) many years on ideas in and around this paper. 
Beall, Jc and Aaron Cotnoir. 2017. "God of the gaps: a neglected reply to God's stone problem." Analysis 77 (4): 681-689.

Belnap. N. D. 1977. "A useful four-valued logic." In Modern Uses of Multiple-Valued Logic, edited by J. M. Dunn and G. Epstein. D. Reidel Press.

Cotnoir, A. J. 2017. "Theism and dialetheism." Australasian Journal of Philosophy 96 (3): 592-609.

Crisp, Oliver D. 2007. Divinity and Humanity: The Incarnation Reconsidered. Cambridge University Press. 2009. God Incarnate: Explorations in Christology. T \& T Clark.

Crisp, Oliver D. and Michael C. Rea (editors). 2009. Analytic Theology: New Essays in the Philosophy of Theology. Oxford University Press.

Cross, Richard. 2005. The Metaphysics of the Incarnation: Thomas Aquinas to Duns Scotus. Oxford University Press. 2011. "The Incarnation." In Oxford Handbook of Philosophical Theology, edited by Thomas P. Flint and Michael Rea. Oxford University Press.

Dahms, John V. 1978. "How reliable is logic?" Journal of the Evangelical Theological Society 21 (4): 369-380.

Dunn, Geoffrey D. 2001. "Divine impassibility and Christology in the Christmas homilies of Leo the great." Theological Studies 62 (1): 71-85.

Dunn, J. Michael. 1966. The Algebra of Intensional Logics. PhD thesis, University of Pittsburgh. . 1976. "Intuitive semantics for first-degree entailments and 'coupled trees."' Philosophical Studies 29: 149-168.

Harman, Gilbert. 1986. Change in View: Principles of Reasoning. MIT Press.

Pawl, Timothy. 2014. "A solution to the fundamental philosophical problem of Christology." Journal of Analytic Theology 2: 61-85. . 2015. "Conciliar Christology and the problem of incompatible predications." Scientia Et Fides 3(2): 85-106.

. 2016. In Defense of Conciliar Christology: A Philosophical Essay. Oxford University Press. 
Priest, Graham. 1979. "The logic of paradox." Journal of Philosophical Logic 8: 219241.

. 1998. "To be and not to be - that is the answer: on Aristotle on the law of noncontradiction." Logical Analysis and History of Philosophy 1: 91-130.

2000. "Motivations for paraconsistency: The slippery slope from classical logic to dialetheism." In Frontiers of Paraconsistency, edited by D. Batens, C. Mortensen, G. Priest, and J-P Van Bendegem. Research Studies Press, Kings College Publications.

. 2006. In Contradiction. Oxford University Press.

Priest, Graham, Jc Beall, and B. Armour-Garb (editors). 2004. The Law of NonContradiction. Oxford University Press.

Routley, Richard. 1979. "Dialectical logic, semantics and metamathematics." Erkenntnis, 14: 301-331.

Routley, Richard and Robert K. Meyer. 1976. "Dialectical logic, classical logic, and the consistency of the world." Studies in East European Thought 16: 1-25.

Tanner, Norman P. 1990. Decrees of the Ecumenical Councils. Georgetown University Press.

Tarski, Alfred. 1956. Logic, Semantics, Metamathematics: papers from 1923 to 1938, translated by J. H. Woodger. Clarendon Press.

Williams. C. J. F. 1968. “A programme for Chistology.” Religious Studies, 3: 513-524. 